\title{
Calcinosis en Esclerosis Sistémica
}

\section{Calcinosis in Systemic Sclerosis}

Paciente de 85 años diagnosticada de esclerosis sistémica con esclerodermia limitada de años de evolución, con ANA positivos a título de 1:5120 patrón anticentrómero, antiScl-70 y anti-Jo negativos. Sus principales manifestaciones clínicas son: Raynaud severo y úlceras digitales a tratamiento con nifedipino y bosentán, hipertensión pulmonar leve, esclerodactilia y calcificación extensa de tejidos blandos en ambas manos, $4^{\circ}$ dedo de mano derecha y $4^{\circ}-5^{\circ}$ dedos de mano izquierda (Figura 1), con deformidades en flexión bilaterales, que se confirman en estudios de radiografía simple (Figura 2). La calcinosis resulta del depósito de cristales de hidroxiapatita de calcio fundamentalmente ${ }^{1}$. Aunque los resultados son en general malos, se han utilizado múltiples tratamientos farmacológicos, como el diltiazem, acenocumarol, colchicina, probenecid, bifosfonatos, ácidoacetilsalicilico, corticoides orales o intralesionales, hidróxido de aluminio, gammaglobulinas endovenosas, minociclina² ${ }^{2}$ rituximab $^{3}$ y otros tratamientos no farmacológicos, como ionoforesis con ultrasonidos y láser $\mathrm{CO2}$, sin que exista una evidencia de mayor eficacia de uno respecto a otro. Algunos autores recomiendan iniciar tratamiento con diltiazem ${ }^{4}$, con posibilidad de combinar tratamientos. La exéresis quirúrgica, puede ser una opción en pacientes con lesiones cálcicas dolorosas y/o afecten la movilidad, antes de que se desarrolle ulceración, dado que el riesgo es importante en esta situación $n^{5}$.

\section{Bibliografía}

1. Makol A, Yetterberg SR. Calcinosis cutis in Systemic Sclerosis. N Engl J Med. 2011; 364:23.

2. Robertson LP, Marshal RW, Hickling P. Treatment of cutaneous calcicosis in limited systemic sclerosis with minocycline. Annals of the Rheumatic Diseases 2003; 62:2.

3. Daoussis D, Antonopoulos I, Liossis SNC, Yiannopoulos G, Andonopoulos AP. Treatment of Systemic Sclerosis-Associated Calcinosis: A case report of rituximabinduced regresión of CREST-related calcicosis and review of the literature. Semin Arthritis Rheum 2012; 41:822-9

4. Palmieri GMA, Sebes Jl, Aelion JA, Moinuddin M, Ray MW, Wood GC, Leventhal MR. Treatment of calcicosis with diltiazem. Arthritis \& Rheumatism 1995; 38:1646-54

5. Balin SJ, Wetter A, Andersen LK, Davis MDP. Calcinosis cutis occurring in association with autoinmune connective tissue disease. The Mayo Clinic Experience with 78 patients, 1996-2009. Arch Dermatol 2012; 148:455-62

\section{Diagnóstico: Calcinosis en esclerosis sistémica con esclerodermia limitada}

\section{Tamara Caínzos Romero, Sabela Sánchez Trigo}

Medicina Interna. Complexo Hospitalario Universitario de Ferrol. SERGAS. Ferrol

Correspondencia: tamara.cainzos.romero@sergas.es

Como citar este artículo: Caínzos Romero T, Sánchez Trigo S

Calcinosis en Esclerosis Sistémica. Galicia Clin 2014; 75 (4): 204

Recibido: 14/05/2014; Aceptado: 25/08/2014
Figura 1. Calcificación en base de $5^{\circ}$ dedo de mano izquierda

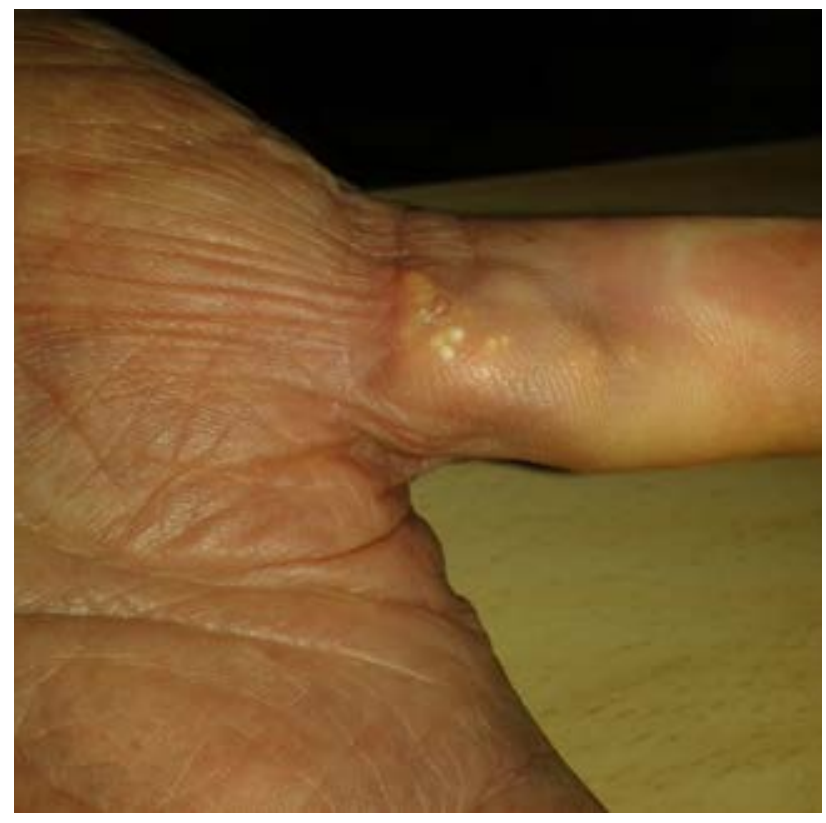

Figura 2. Radiografía simple de mano que confirma extensas calcificaciones de tejidos blandos
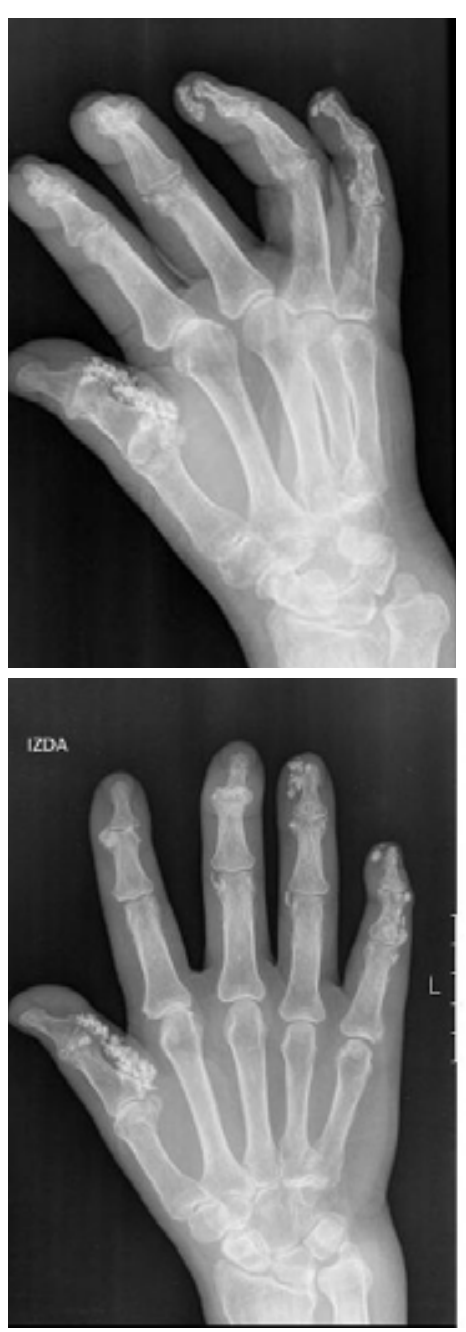